\title{
AN UNDERGRADUATE RESEARCH COURSE AIMED AT FURTHERING THE WEB
}

\author{
Michael Wollowski ${ }^{l}$
}

\begin{abstract}
The world-wide web presents a new frontier in science and engineering. There are many problems yet to be solved or even formulated. Many students are fascinated by the world-wide web and a good number of our own students have created rather sophisticated web-sites. The major aim of this course is to introduce them to skills and habits that enable them to develop new technologies and applications for the web. This is not necessarily an easy task, as engineers are traditionally trained to solve problems rather than formulate interesting problem statements. The centerpiece of the course is the research project. Through it, students investigate and develop new technologies or applications for the web. Additionally, we study major areas in which the web has an impact.
\end{abstract}

Index Terms - project course, undergraduate research, world wide web.

\section{INTRODUCTION}

The world-wide web offers a new frontier in science and engineering. There are many problems yet to be solved or even formulated. Many students are fascinated by the worldwide web and a good number of our own students have created rather sophisticated web-sites. The major aim of this course is to introduce students to the skills and techniques of performing research, using the world wide web as a domain.

While there are many other domains for research in Computer Science, due to the newness of the web, there is no long lead time required to gain a depth of knowledge required to perform research. Furthermore, when students do gain a certain understanding of the web, they can make true contributions to this field and not mere rediscoveries of established results. This is what makes the web particularly appealing for a research course.

The main reason why this course is offered as a way to learn about the research process is a rather practical one. Our students are very good at solving problems that are fairly well-defined. However, our students seem to have difficulties when it comes to formulating interesting new problems or questioning existing solutions. It simply seems to be a shame not giving our students an opportunity to develop their creative and research abilities. As such, this course attempts to balance our students' education.

Another reason for offering this course is that the web is my research area and as such, I hope to involve students in my research.
Finally, this course is a lot of fun to teach.

In the following section, we highlight some of the main features of the course. We then introduce some of the major components of the course and how they interact. We describe some of the student projects and end the paper with an evaluation of what worked and ideas for future installments of the course.

\section{About The Course}

Due to the domain of the research, this course is a combination of a research course with goals such as found in $[3,5]$ and a course on invention, such as described in [2, 4].

A major aspect of the course is the project. The project is done in groups of three or four students. The aim of the project is to develop some new web-technology, to apply given technology in new ways, or to investigate an important issue related to the web. While the aim of some of the group projects was higher than that of others, all of them investigated topics that were new at the moment. All groups had to report their project in a paper and present it to the class.

While the project lasted for the length of the quarter, ten weeks are still not sufficiently long when it comes to the kind of projects that our students tackled.

A good number of the students enrolled in this course already had a solid background in a range of web tools. Some of them developed and maintained small web sites, such as discussion forums or web sites for small companies. However, some students did not have any web-authoring skills beyond HTML.

While the majority of the participants are Computer Science majors, there are usually a couple of Computer Engineering majors in this course. This proved helpful for some of the projects.

\section{COURSE COMPONENTS}

The first four weeks of the course were spent on identifying interesting projects and to provide students with tools to implement their project, if they decided to do so. Table I presents a rough course schedule. This phase had two components to it, one in which we attempted to grasp the nature of the web, and one in which we brainstormed project ideas and attempted to form groups of students interested in similar projects.

\footnotetext{
${ }^{1}$ Michael Wollowski, Computer Science Department, Rose-Hulman Institute of Technology, Terre Haute, IN 47803 wollowski@ rose-hulman.edu 0-7803-6669-7/01/\$10.00 @ 2001 IEEE

$31^{\text {st }}$ ASEE/IEEE Frontiers in Education Conference

October 10 - 13, 2001 Reno, NV 


\section{Session S3A}

\section{Setting our Sights}

We begin the course by setting our sights on what we wish to accomplish in it. To do so, we read a very fascinating interview with Jeff Bezos [1], the founder of Amazon.com. The article highlights the kind of research Bezos did before founding his company. More importantly, it explains the simplicity of his idea and a certain amount of cunning that went into starting an online bookstore. It also gives a brilliant insight into the mind and motivations of one of the pioneers of the web. In essence the article highlights the kind of skills and techniques we want to explore during the course.

\section{Grasping the web}

In order to get a sense of worthwhile projects, we attempt to grasp the nature of the web. We begin by developing a classification hierarchy of web-sites. To satisfy this exercise, students could either devise their own hierarchy evaluate existing hierarchies.

We continue the evaluation of the web by developing four lists of web uses: (i) well-established and useful websites, (ii) uses of the web that have become stale, (iii) upand-coming uses, and (iv) uses that may be part of the second wave. This was the first challenge to think about the future. A second challenge followed suit. In order to develop a sense of the limitations of the web, students were asked to think about anything that could never be accomplished with the web.

Just before the project proposals were due, my students had to write a science-fiction essay in which they had to create a future world that is dominated by the web. By employing the tool of a science fiction essay, I was hoping to put as few constraints on their imagination as possible and thereby stimulate it. There is a tendency of our students to limit their imagination by what they think is doable. Consequently, this was not an easy homework and the results were mixed. There were some fascinating and original papers, but there were also a lot of papers that merely digested the brief discussions about the future that we had in class.

\section{Discovering student projects}

The only requirement that is placed on the project is that it advances the web in one way or other, thereby giving my students wide latitude in selecting a topic. In the past I have been positively surprised by this approach. While students seem to be naturally interested in projects that develop new technologies or applications for the web, I do encourage students to investigates important issues related to the web through a more traditional research paper.

During the most recent time I offered this course, I took a very active role in the project proposal stage. This was in response to the kind of proposals I received the year before.
During that time, I had one outstanding project and many that were not that interesting. The project that stood out wired a soda machine to the web. The project stood out for all of the right reasons. Each of the four group members had expertise in one of the four areas of the project. One member programmed the web-site, another one installed and set-up all the software on the computer as well as programmed the database. A third group member programmed the parallel port, which interacts with the relay box that governs the dropping of soda cans. The fourth student built the relay box in consultation with a professor from the Electrical Engineering department. All four students were highly motivated and they managed to have a running version by the end of the quarter. Several students continued to work on the project after the course was over and one of them still maintains the software. This project generated a lot of news coverage. It was written up in the local newspaper, and a shortened version of the article appeared all over the state and as far away as Florida and Arizona. A local TV station produced a rather engaging report of the project. Naturally, the group enjoyed this attention, and it gave them just reward for all the extra work that they put into this project.

While the success of this one project was very satisfying to me, this time, I wanted to ensure that all projects are interesting and advance the web in one way or other. I gave my students about four weeks to propose a project and form groups. In order to ensure that the thinking started on the first day of classes, and not the night before the proposals were due, I did the following.

To begin, I told my students on the first day of classes when the proposals for the project were due. I also explained the kinds of project proposals I would accept. This may seem like a trivial exercise, but it highlighted very early on the importance that I placed in the project and the discovery of an interesting topic.

We held two "jam sessions". They took place during the first two Fridays of the quarter. The major goals of those sessions were (i) to get students to think freely about possible projects, (ii) to give students feedback about solutions that already address a project proposal, and (iii) to aid in the formation of groups.

For the first jam session, every student had to think about and briefly present at least one idea for a project. It did not matter whether the project was feasible or not. The first jam session proved to be a roaring success as it achieved exactly what I hoped it would. The majority of the students had ideas for several projects and students gave each other feedback on already existing solutions. Based on project proposals that were similar, some groups began to form.

For the second jam session, I asked students to start forming groups with other students of like interests and have a group presentation of a project proposal. I asked groups to perform an initial background search (using the web) to ascertain the existence of similar or like projects, as well as to refine the project proposals.

\section{0-7803-6669-7/01/\$10.00 @ 2001 IEEE}

$31^{\text {st }}$ ASEE/IEEE Frontiers in Education Conference

October 10 - 13, 2001 Reno, NV 
The second jam session too was a big success. The majority of the groups had formed and they had a pretty good idea of the kind of project they wanted to tackle.

A draft of a formal project proposal was due at the end of the third week. Among others, it had to address prior work. I reviewed the proposals over the weekend and returned them on Monday. Not all of the proposals were accepted. For example, some students proposed projects for which they did not have a partner and which were of a magnitude such that they could not have tackled the problem by themselves. Also, some of the projects did not satisfy my requirement of advancing the web. During the following week, I met with some students individually to discuss possible project ideas and the idea of joining other groups.

During the fourth week, I outlined several project proposals that I myself developed, in order to help those students who's project ideas were still not settled. In part, I was hoping that some of the students would jump on this opportunity. Formal project proposals were due at the end of the fourth week. Some groups went through three project proposals, before finally settling on one.

I was very happy with the project proposal phase of the project. By the time the dust settled, the project proposals were interesting and promising.

\section{Providing a common ground}

In addition to attempting to get a grasp on the web and to discover interesting student project, I provided a brief introduction to Perl, a popular programming language for developing web applications. This way, students who did not have any experience developing web applications had the ability to implement their project.

This concluded the first part of the course. It took four weeks, and the Christmas break provided a natural break.

TABLE I

COURSE SCHEDULE

\begin{tabular}{ll}
\hline Week & Topics \\
\hline 1 & Taking stock in the web \\
2 & The immediate future of the web \\
3 & Perl, major web technologies \\
4 & The far future \\
5 & Virtual classroom \\
6 & Shopping \\
7 & Networks \\
8 & XML, XSL \\
9 & Confidentiality and security \\
10 & Project presentations \\
\hline
\end{tabular}

\section{THE PROJECTS}

After the project proposals had been accepted and the groups were formed, the next challenge was to ensure steady progress on the projects. To accomplish this, I gave my students one of the four class periods per week off. Instead, I had a weekly meeting with each of the groups. During those meetings, we discussed the progress that was made as well as any issues on which the group desired input from me. We also discussed the progress that they hoped to make during the following week.

In addition to the group meetings, every group was required to give at least one presentation of their state of the project to the entire class. We usually had about one such presentation per class period.

During the last week of classes, each group gave a formal presentation of their work. Among others, they had to address why their work was innovative. Finally, all projects had to be written up in a paper.

Below is a brief description of each of the projects during the most recent offering of the course.

RHINO: The aim of this project was to create a website that integrates several existing sites which contain administrative information of the institute. This includes phone numbers, schedules, and even lists of student pictures enrolled in a particular course. Originally, the aim was much larger, enabling users to configure their own information portal to much of the information available on campus. However, these goals had to be abandoned, partly due to some unexpected road-blocks. The project prompted a flurry of campus activities aimed at sorting out the confidentiality of student pictures. This went as far as temporarily disabling the ability to view the pictures. In class, we discussed some of these issues and possible solutions to them. Based on our conclusions, RHINO was augmented, so that students can control who has access to their pictures and phone numbers. While this project did not necessary advance the web in the way I hoped, it did end up solving some real-world problems that were of concern to the campus community by using technology in innovative ways.

P2P: The aim of this project was to study ways of reducing internet traffic. Students in this group studied several services, such as Akamai, Gnutella, and Squid servers, that reduce internet traffic by storing pictures, and other files on local servers. Based on testing and analytical evaluation of existing technology, they proposed their own, imaginative scheme and evaluated it. This group too worked on a timely project. During the quarter in which this course was offered, an institute-wide discussion of the bandwidth of our internet connection began. A town-hall meeting was held, and several articles were published in the student paper. This group, as well as some other students in the course actively searched for solutions to the bandwidth problem. They ended up installing a Squid server, and devised a web-site informing students what they can do to reduce internet traffic.

A science web-site: The aim of this project was to develop a web-site for scientists and people interested in science for the purpose of exchanging information and ideas. While there are science newsgroups, sites associated with science magazines, and K12 science sites, there are currently no such sites for scientists and people interested in science.

\section{0-7803-6669-7/01/\$10.00 @ 2001 IEEE}

$31^{\text {st }}$ ASEE/IEEE Frontiers in Education Conference

October 10 - 13, 2001 Reno, NV 
One of the aims of this project was to develop a site that integrates articles and discussions.

WebWash: This project was a variation of a project from the year before. Instead of hooking up a soda machine to the web, this project wanted to connect a washing machine to the web. There are several benefits to such a project. Students tend to do their laundry Sunday evening. This creates a scheduling problem, which can easily be solved by a web site with an electronic sign-up sheet. Such a web site can also handle the accounting, as well as monitor the progress of the washing machine. This project was not as successful as the soda machine project. The major stumbling block was, ironically, that the machine was already controlled by a micro-processor. We never obtained the documentation for the processor and even though the group tried very hard to reverse engineer the behavior of the micro-processor, they could not establish the operating procedures of the washing machine. This project would have had much more success in the framework of the semester system.

RadioGuide.com: The aim of this project was to provide means of searching for radio shows. This way, if one misses a favorite show, one can consult the site to ascertain if the show is web-cast by another station during a different time period. This group proposed a design for this web-site. As part of their research, they visited a local radio station and discussed some technical and legal issues.

A better Newsgroup reader: The aim of this project was to investigate different ways of displaying newsgroups, as well as the possibility of automatically extract FAQs from a newsgroup. Even though the project started late and there was only a single group member, it nevertheless made some interesting progress.

A search engine for departmental course information stored in XML: Realizing the potential of $\mathrm{XML}$, the aim of this project was to transfer departmental course information into XML format and to develop a search engine for it. This group had to wrestle with some rather technical details, a lot of times undocumented. They got a real sense of what it means to work in an area that is evolving. I expect that this project laid the foundation for future projects extending it in many ways.

I/R port for the web-driven soda machine: The aim of this project was to extended the functionality of the webdriven soda machine, by adding an I/R port to it. This potentially enables one to order a soda with a PDA or cellphone. Unfortunately, there were some rather technical details that could not be resolved.

A graphical query editor for boolean search expressions: The aim of this project was to develop a graphical editor for boolean expressions. Such an editor could act as a front-end to a search engine. The quality of a web search can be significantly increased by starting out with a reasonable sized boolean query. However, most webusers are unfamiliar with the rules of precedence when it comes to boolean operators. This project was aimed at resolving these issues.

Wireless communication with the soda machine: The idea of this project was developed a while ago, after we demonstrated the web-driven soda machine to the president of the company that donated the soda machine. We were hoping to sell the idea to their company, but they were not interested. Instead, they pointed out a real problem for which they are looking for a cheap solution. It is the problem of knowing the stock of a vending machine. This group successfully investigated several ways to communicate with a vending machine in a wireless fashion. During the current quarter, one of our students is enrolled in an directed study course in which they plan to implement one of those proposals.

\section{Continued Evaluation OF THE WeB}

During the remainder of the quarter, students spent the majority of their time on the project. Nevertheless, we continued to discuss important areas of the web. We now embarked on a more in-depth study of major uses and technologies of the web.

To give my students a sense of the importance of observing trends in the field in which one wants to make an impact, I asked them to bring to class current articles and reports that dealt with pressing issue related to the web. This turned out to be an interesting feature of the course. A good number of students brought in articles or interesting web sites, or mentioned stories that they read in the news. We discussed them and occasionally asked some of those students to give us more in-depth follow-up reports on what they reported.

Additionally, each student had to present a set of newspaper articles. I furnished students with articles from a collection of newspaper clippings that I gathered during the prior year. One of the questions that we always asked was how a presented technology could be extended to other areas.

Some of the major topics that we discussed were: online shopping, the virtual classroom, networks, and confidentiality. In order to experience a virtual classrooms, we held our discussions of this topic on the newsgroup associated with the course. To my surprise, our students are not quite ready to give up the physical class room experience.

I continued to introduce technologies that were useful for those students who implemented their project. Among others, I introduced how to interface to a database, as well as the underlying technology of search engines. Towards the end of the quarter, I introduced XML and its associated technologies. 


\section{Session S3A}

\section{EVALUATION AND CONCLUSIONS}

Due to the popularity of the web, it receives a lot of press coverage. This is very beneficial in demonstrating that their work has the potential to make a difference. It also serves for ready course material in the absence of a suitable textbook for a course like this. During the past two times I offered the course, we got extremely lucky as to the press coverage of the web. During the winter quarter of 1999/2000 the dotcom bubble was at its largest expanse; during the winter quarter of 2000/2001, it burst.

On the subject of dealing with current problems, oncampus discussion of the size of our internet connection and the confidentiality of student pictures lead to in-class discussion of these issues. It stimulated some students to think about solutions to these problems. I had several out-ofclass discussions on these issues, and in response to them, asked some of the students to present their ideas to the entire class. Such campus events cannot be planned and are a welcomed starting point for discussion. Again, it gave my students a sense that they are working on real-world problems.

While student presentations of newspaper articles provided us with a springboard for discussing pressing issues related to the web, they lacked a certain depth. The next time I offer the course, I plan to use newspaper articles as well as research papers such as published in the proceedings of the International World Wide Web Conference series [6].

In addition to reporting on current developments of the web, students were asked to report on interesting web-sites. Towards the end of the quarter, they got into the spirit of things and reported on unusual web-sites. A certain theme evolved, probably best paraphrased by "Things our instructor may wish to connect to the internet, but never thought of." This showed that one of the goals of the course, to keep an open eye towards interesting developments, was accomplished.

During the prior year when this course was offered, every student had to give a "tool-time" presentation which demonstrated and discussed some web-technology. This segment was omitted during this past quarter and I am happy I did so. The presentations were mostly on technologies that the presenter already knew and a good number of students in the class were also aware of it.

The project selection and supervision turned out to be rather successful. Nevertheless, the progress of some of the groups slowed down somewhat during the middle of the quarter. I plan to address this problem by asking students to keep a journal of their work. People seem to have a lot of luck with this tool [2, 4]. Furthermore, I plan to ask each group to give a formal presentation on the status of their project, midway through the project. This is instead of informal presentation spread out over the second part of the quarter.
It became obvious that projects which develop actual technology, such as wiring a soda-machine or washing machine to the web heavily depend on the prior knowledge of the group members. In the absence of prior knowledge, I plan to curtail such projects or at least ensure that students with the right kind of expertise join such projects. I was very pleased with the topics and accomplishments of projects that had a more theoretical bend and plan to encourage more of those.

In general, it appears that most projects could have benefited from five more weeks of work, such as available in the semester system. The quarter system seriously constrains the kind of projects that can be accomplished with a satisfactory degree of success. One of the solutions to this problem would be to assign group projects at the beginning of the quarter. Students could select a project of their liking, but would otherwise have no influence on the process of developing an interesting project proposal. To compensate, a second project could be assigned in which students develop a project proposal. Those proposals could then be used for subsequent installments of the course.

\section{REFERENCES}

[1] Bayers, C., "The Inner Bezos", WIRED, Vol 7, No 3, March 1999, also available at: www.wired.com/wired/archive/7.03/bezos.html.

[2] Carlson, L., Sullivan, J., Poole, S., Piket-May, M., "Engineers as Entrepreneurs: Invention and Innovation in Design and Build Courses", Proceedings of the 29th Frontiers in Engineering Conference, pp. 11a6-4 - 7, San Juan, P.R., 1999.

[3] Gates, A.Q., Teller, J.T., Bernat, A., Delgado, N., Della-Piana, C.K., "Meeting the Challenge of Expanding Participation in the Undergraduate Research Experience", Proceedings of the 30th Frontiers in Engineering Conference, Kansas City, KA, 2000.

[4] Mehalik, M.M., Richards, L.G., Gorman, M.E., "Turning Students into Inventors and Entrepreneurs: The Continuing Evolution of a Course in Invention and Design", Proceedings of the 29th Frontiers in Engineering Conference, pp. 11a6-8 - 12, San Juan, P.R., 1999.

[5] Passos, N.L., Carpenter, S. B., "True Undergraduate Research: Foundations for Graduate Studies and Critical Thinking", Proceedings of the 29th Frontiers in Engineering Conference, pp. 13c5-7 - 12, San Juan, P.R., 1999.

[6] Proceedings of the 10th International World Wide Web Conference www10.org. 